University of Nebraska - Lincoln

DigitalCommons@University of Nebraska - Lincoln

2012

\title{
Pore-Scale Characterization of Biogeochemical Controls on Iron and Uranium Speciation under Flow Conditions
}

\author{
Carolyn I. Pearce \\ Pacific Northwest National Laboratory, carolyn.pearce@pnnl.gov \\ Michael J. Wilkins \\ Pacific Northwest National Laboratory \\ Changyong Zhang \\ Pacific Northwest National Laboratory \\ Steve M. Heald \\ Argonne National Laboratory \\ James K. Fredrickson \\ Pacific Northwest National Laboratory, jim.fredrickson@pnl.gov \\ See next page for additional authors
}

Follow this and additional works at: https://digitalcommons.unl.edu/usdoepub

Part of the Bioresource and Agricultural Engineering Commons

Pearce, Carolyn I.; Wilkins, Michael J.; Zhang, Changyong; Heald, Steve M.; Fredrickson, James K.; and Zachara, John M., "Pore-Scale Characterization of Biogeochemical Controls on Iron and Uranium Speciation under Flow Conditions" (2012). US Department of Energy Publications. 242.

https://digitalcommons.unl.edu/usdoepub/242

This Article is brought to you for free and open access by the U.S. Department of Energy at DigitalCommons@University of Nebraska - Lincoln. It has been accepted for inclusion in US Department of Energy Publications by an authorized administrator of DigitalCommons@University of Nebraska - Lincoln. 
Authors

Carolyn I. Pearce, Michael J. Wilkins, Changyong Zhang, Steve M. Heald, James K. Fredrickson, and John M. Zachara 


\title{
Pore-Scale Characterization of Biogeochemical Controls on Iron and Uranium Speciation under Flow Conditions
}

\author{
Carolyn I. Pearce, ${ }^{* \dagger}{ }^{\dagger}$ Michael J. Wilkins, ${ }^{\dagger}$ Changyong Zhang, ${ }^{\dagger}$ Steve M. Heald, ${ }^{\dagger}$ Jim K. Fredrickson, ${ }^{\dagger}$ \\ and John M. Zachara ${ }^{\dagger}$
}

${ }^{\dagger}$ Pacific Northwest National Laboratory, Richland, Washington 99352, United States

${ }^{\ddagger}$ Argonne National Laboratory, Argonne, Illinois 60439, United States

\section{Supporting Information}

ABSTRACT: Etched silicon microfluidic pore network models (micromodels) with controlled chemical and redox gradients, mineralogy, and microbiology under continuous flow conditions are used for the incremental development of complex microenvironments that simulate subsurface conditions. We demonstrate the colonization of micromodel pore spaces by an anaerobic Fe(III)-reducing bacterial species (Geobacter sulfurreducens) and the enzymatic reduction of a bioavailable $\mathrm{Fe}$ (III) phase within this environment. Using both Xray microprobe and $\mathrm{X}$-ray absorption spectroscopy, we investigate the combined effects of the precipitated $\mathrm{Fe}$ (III) phases and the microbial population on uranium biogeochemistry under flow conditions. Precipitated $\mathrm{Fe}$ (III) phases within the micromodel were most effectively reduced in the presence of an electron shuttle (AQDS), and $\mathrm{Fe}$ (II) ions adsorbed onto the precipitated mineral surface without inducing any structural change. In the absence of $\mathrm{Fe}(\mathrm{III}), \mathrm{U}(\mathrm{VI})$ was effectively reduced by the microbial population to insoluble $\mathrm{U}(\mathrm{IV})$, which was precipitated in discrete regions associated with biomass. In the presence of Fe(III)

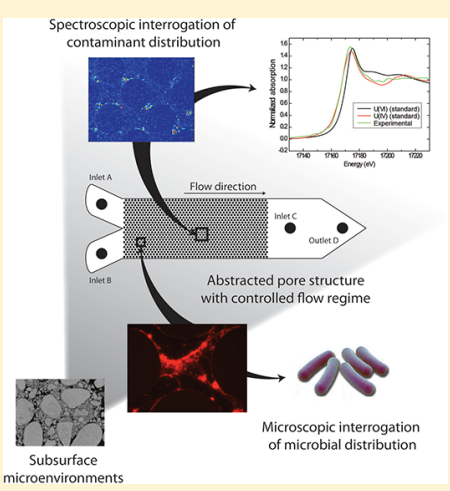
phases, however, both U(IV) and U(VI) could be detected associated with biomass, suggesting reoxidation of U(IV) by localized $\mathrm{Fe}$ (III) phases. These results demonstrate the importance of the spatial localization of biomass and redox active metals, and illustrate the key effects of pore-scale processes on contaminant fate and reactive transport.

\section{INTRODUCTION}

Biogeochemical cycling in subsurface environments plays a key role in the fate and reactive transport of contaminant metals and radionuclides. ${ }^{1}$ Uranium is an important subsurface contaminant as either highly soluble $\mathrm{U}(\mathrm{VI})$, or sparingly soluble U(IV). Laboratory experiments have demonstrated that both microbially catalyzed enzymatic ${ }^{2,3}$ and abiotic reduction of $\mathrm{U}(\mathrm{VI})$ can occur, ${ }^{4-6}$ and these processes have been observed in the environment. ${ }^{7,8}$ Typically, metal-reducing bacteria in the subsurface (e.g., Geobacter, Shewanella) are responsible for both direct microbial $U$ reduction and indirect $U$ reduction by production of biogenic $\mathrm{Fe}(\mathrm{II}) .{ }^{4}$ Homogeneous $\mathrm{U}(\mathrm{VI})$ reduction by aqueous $\mathrm{Fe}$ (II) does not occur, ${ }^{9}$ but $\mathrm{Fe}$ (II) sorbed onto $\mathrm{Fe}(\mathrm{III})$ oxide surfaces, ${ }^{9}$ and structural $\mathrm{Fe}(\mathrm{II})$ in green rust ${ }^{10}$ and magnetite, ${ }^{11}$ have been implicated in abiotic $U$ reduction. Once reduced, the reoxidation of $U(I V)$ can be mediated by the presence of $\mathrm{Fe}$ (III) phases; $\mathrm{Fe}$ (III) (hydr)oxides may undergo reduction with the concurrent oxidation of U(IV). ${ }^{12}$ However, given the insoluble nature of both $\mathrm{Fe}(\mathrm{III})$ and $\mathrm{U}(\mathrm{IV})$, close spatial contact is presumably necessary for this redox reaction to occur. Therefore, the spatial distribution of both metalreducing bacteria and $\mathrm{Fe}$ (III) mineral phases in the subsurface may exert a strong control on uranium speciation, and as a result the fate and transport of this contaminant.

In laboratory batch experiments, homogeneous mixing enables optimal conditions for interactions between biomass and redox active elements that drive these processes. In subsurface environments, however, porous sediments and groundwater flow may result in spatially separated systems, and nonuniform chemical and/or redox gradients at the fluidfluid and fluid-mineral interfaces, where biomass and redox active elements may not interact as freely. Aquifer materials can exhibit physical and chemical heterogeneity over a wide range of scales. At the macro scale (i.e., continuum to field scales), depositional artifacts might result in contrasting hydraulic conductivity across meter distances in the subsurface. $\mathrm{Li}$ et al. ${ }^{13}$ studied physicochemical heterogeneity controls on uranium bioreduction at the Rifle site and showed uranium bioreduction rates depended to a large degree on spatial distribution of hydraulic conductivity and bioavailable Fe(III). ${ }^{13}$ At the micro scale (i.e., pore scale), the presence of grain coatings on sands and gravels, and the fines themselves (e.g., silts, clays), can result in the development of microenvironments, chemical/ redox gradients, and transition zones. Notable examples of microscale controls on uranium transport, speciation, and reactivity include those of McKinley et al., who demonstrate that the microscale chemical environment can affect the removal of $\mathrm{U}(\mathrm{VI})$ in the form of uranyl silicate from pore water in vadose Hanford formation sediments, ${ }^{14}$ and Liu et al.

Received: March 16, 2012

Revised: June 12, 2012

Accepted: June 25, 2012

Published: June 25, 2012 
who demonstrate that aqueous $\mathrm{U}(\mathrm{VI})$ speciation evolves as solution composition changes from solution/sediment interactions, affecting the rate of bioreduction. ${ }^{15}$ Biogeochemical cycling of key redox active species, such as iron and uranium, is dominated by pore-scale interactions, with strong effects resulting from the coupling of chemical reactions, physical transport, and microbiological processes. ${ }^{13,16-18}$ However, despite the importance of these regions in contaminant fate and transport, they remain difficult to study experimentally and to model. Destructive bulk analysis of material from these zones is unable to account for the microscale spatial component of biogeochemical reactivity, while the technology does not currently exist to observe such processes at relevant scales in situ. This has resulted in a paucity of data to constrain and validate pore-scale reactive transport models.

Here, microfluidic pore structures etched into silicon substrate are used as two-dimensional model subsurface porous media systems (i.e., micromodels) to investigate the spatial controls exerted by biomass and $\mathrm{Fe}$ phases on $\mathrm{U}$ fate and transport. These devices allow the control and manipulation of mineralogy, flow rate, and microbial population, making it possible to interrogate microbiological and geochemical reactions coupled with pore-scale hydrodynamic processes (e.g., advection, diffusion, and mixing). ${ }^{19}$ To date, characterization of biogeochemical reactive transport in micromodels have been limited to optical imaging including bright field, ${ }^{20,21}$ fluorescence imaging, ${ }^{22,23}$ and Raman microscopy. ${ }^{24}$ In this paper, a silicon micromodel, in combination with bright field/ fluorescence imaging and synchrotron X-ray fluorescence mapping/spectroscopy, is used to investigate (i) the colonization of a homogeneous pore network by a model $\mathrm{Fe}$ (III)-reducing bacterium; (ii) the microbially induced reduction of an $\mathrm{Fe}$ (III) phase precipitated within the pore network; and (iii) the subsequent redox interactions with $\mathrm{U}(\mathrm{VI})$ under advective flow conditions. X-ray microprobe (XMP) and X-ray absorption spectroscopy (XAS) are used to probe the distribution and oxidation state of $\mathrm{Fe}$ and $\mathrm{U}$ within the micromodel. Results indicate that the complex interplay between the microbial population and terminal electron acceptors (Fe, $\mathrm{U})$ will affect $U$ mobility in the subsurface across small spatial scales and under flow conditions. XMP has been previously used to characterize $\mathrm{Fe}$ speciation in batch samples, ${ }^{25}$ in capillary columns under flow conditions, ${ }^{26}$ and in ex-situ measurements of U(VI) bioreduction in contaminated soil samples. ${ }^{27-29}$ To the best of our knowledge, this is the first time that XMP/XAS have been used to characterize $\mathrm{U}(\mathrm{VI})$ bioreduction in a pore network containing both $\mathrm{Fe}(\mathrm{III})$ reducing organisms and $\mathrm{Fe}(\mathrm{III})$ mineral phases and under flow conditions.

\section{MATERIALS AND METHODS}

Micromodel Experiments. Micromodels were fabricated in silicon substrates using a microfabrication method involving photolithography and plasma etching techniques. ${ }^{22,30}$ Details of the fabrication method are included in the Supporting Information. A uniform pore network of $2 \times 1 \mathrm{~cm}^{2}$ (length $\times$ width) was fabricated with grain diameters of $300 \mu \mathrm{m}$, depths of $35 \mu \mathrm{m}$, pore spaces of $180 \mu \mathrm{m}$, pore throat of $40 \mu \mathrm{m}$, and an average porosity of 0.39 . The main pore network was connected to two inlet channels (Figure S1, Inlet A and Inlet B), which allowed delivery of media containing electron donors and acceptors separately to generate a mixing zone down the center of the pore network (Figure S1). A third inlet (C) next to the pore network in the outlet channel allowed injection of a chemical solution to quench further reaction in the outlet (D). Continuous injection of media was maintained at representative groundwater flow rates (with a Darcy velocity of approximately $1 \mathrm{~cm} \min ^{-1}$ ), using a pair of milliGAT LF smooth low flow pumps (Global FIA Inc., Fox Island, WA) controlled by FlowZF software. All solutions used in the study were maintained at $31{ }^{\circ} \mathrm{C}$ in a heating block to prevent bubble formation in the micromodel as a result of heat transfer from the pumps. When required, $\mathrm{Fe}$ (III) phases were precipitated down the center of the pore networks via the addition of an aerobic basal salt medium ${ }^{31}$ through one inlet and an anaerobic basal salt medium containing $\mathrm{FeCl}_{2} \cdot 4 \mathrm{H}_{2} \mathrm{O}(15 \mathrm{mmol} / \mathrm{L})$ through the other inlet, mimicking the boundary between oxidized and reduced subsurface zones (Figure S2). The $\mathrm{pH}$ of both solutions was maintained at $\sim 6.5$. A poorly crystalline $\mathrm{Fe}(\mathrm{III})$ phase was precipitated within the central mixing zone down the length of the model; this process was continued until no further growth of the precipitate was observed $(\sim 2 \mathrm{~h})$. In principle, the transverse width of the precipitate was a function of contact and mixing of the two solutions; cessation of precipitate growth was thus consistent with physical loss of contact between the two solutions. During the Fe precipitation experiment, an acid solution $(\mathrm{HCl}, \mathrm{pH}=1.5)$ was injected through inlet $\mathrm{C}$ using a syringe pump (Harvard Instruments) at a volumetric flow rate equal to one-half of the total flow rate through the pore network to prevent precipitation and clogging of the outlet. An independent test using a fluorescent tracer showed minimal flow disruption in the pore network due to injection through $\mathrm{C}^{24}$

Microbial Growth and Exposure to U(VI). Derek Lovley at the University of Massachusetts Amherst kindly provided cultures of a Geobacter sulfurreducens strain that constitutively expressed a fluorescent green fluorescent protein (GFP), allowing the visualization of biomass using epifluorescence microscopy. These cultures were maintained on a freshwater medium (FWM) with acetate $(10 \mathrm{mmol} / \mathrm{L})$ and fumarate (10 $\mathrm{mmol} / \mathrm{L}$ ) as electron donor and acceptor, respectively, as described previously. ${ }^{31}$ All micromodels, tubing, and fluid connections were sterilized by rinsing with a $2 \%$ bacdown solution (Decon Laboratories Inc., King of Prussia, PA) prior to inoculation. Inoculation of the micromodels was carried out in two steps. First, one set of micromodels was inoculated by flowing a stock solution of G. sulfurreducens cells in FWM $(\sim 1$ $\times 10^{7}$ cells $/ \mathrm{mL}$ ) through both inlets for $48 \mathrm{~h}$. The media was then switched so that FWM with acetate $(10 \mathrm{mmol} / \mathrm{L})$ was added through one inlet and FWM with fumarate $(10 \mathrm{mmol} / \mathrm{L})$ was added through the other. Cell growth was maintained under these conditions for 4 weeks. Next, a second set of micromodels was subsequently inoculated by adding the effluent from the first set of micromodels, which contained cells that had been conditioned to growth in a micromodel environment, through both inlets for $48 \mathrm{~h}$. After this time, the media was again switched so that FWM with acetate (10 $\mathrm{mmol} / \mathrm{L}$ ) was added through one inlet and FWM with fumarate $(10 \mathrm{mmol} / \mathrm{L})$ was added through the other and cell growth was continued for a further 4 weeks. This two-step inoculation method was most effective for maintaining consistent biomass growth in the micromodel.

Two sets of experiments were conducted with and without $\mathrm{Fe}$ (III) oxide precipitates in the micromodel. In the first set of experiments, FWM containing either acetate $(10 \mathrm{mmol} / \mathrm{L})$ or fumarate $(10 \mathrm{mmol} / \mathrm{L})$ was introduced to the micromodel 

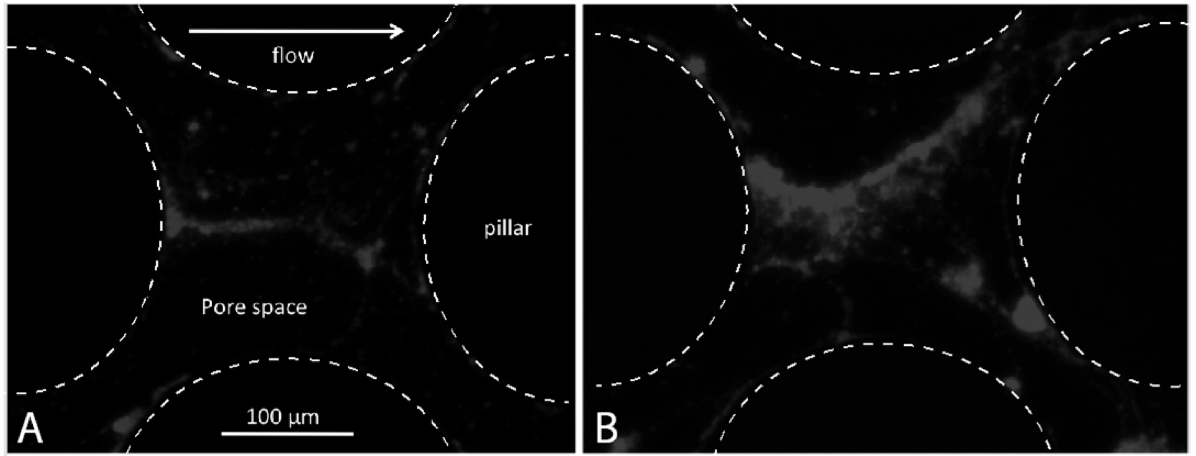

Figure 1. Fluorescent microscope images of Geobacter biomass growth within the pore network. Cells colonize the downstream side of the grains, and growth extends into the middle of the pore space. Growth is shown after 22 (A) and 32 (B) days.

through separate inlets to establish cell growth. In the second set of micromodel experiments containing Fe(III) oxide as an electron acceptor, FWM containing acetate was introduced through both inlets but one inlet was supplemented with the electron shuttle anthraquinone-2,6-disulfonic acid (AQDS, 0.2 $\mathrm{mmol} / \mathrm{L}$ ) as a humic acid analog to facilitate electron transfer. ${ }^{32}$ The Fe(III) oxide precipitate effectively acted as an impermeable barrier down the mixing zone in the center of the micromodel and prevented contact between the two solutions. Diffusion of solution through the $\mathrm{Fe}$ (III) oxide precipitate is possible; however, given the rate of flow in the micromodel, it is unlikely that diffusion would have a significant impact. Thus, this micromodel was considered as two physically separated experiments to investigate biogenic $\mathrm{Fe}(\mathrm{III})$ reduction; (i) in the presence of AQDS, which can transfer electrons from the G. sulfurreducens cells to the $\mathrm{Fe}$ (III) oxide without the requirement for physical contact; and (ii) in the absence of AQDS, where physical contact is required, as it is known that $G$. sulfurreducens cannot produce endogenous electron shuttling moieties. ${ }^{33}$ Growth was continued under these conditions for a subsequent 4 week period, after which the FWM containing fumarate was switched to FWM containing uranyl nitrate (6 $\mu \mathrm{mol} / \mathrm{L})$ and for the $\mathrm{Fe}(\mathrm{III})$ oxide-containing micromodel, both inlets were switched to FWM containing acetate (10 $\mathrm{mmol} / \mathrm{L})$ and uranyl nitrate $(6 \mu \mathrm{mol} / \mathrm{L})$. Flow was continued for a further 4 weeks, after which it was stopped and the saturated micromodels were sealed under a $\mathrm{N}_{2}$ atmosphere in a glovebox for synchrotron XMP/XAS. Due to the flow rate and the small pore volume, residence times within the micromodel were short $(\sim 1 \mathrm{~min})$ and therefore it was not possible to detect subtle changes in solution chemistry over the course of the experiment. However, influent and effluent samples were collected periodically (over $12 \mathrm{~h}$ to obtain sufficient sample for analysis) and U(VI) was analyzed with a kinetic phosphorescence analyzer (Chemchek Instruments, Richland, WA), to confirm that $U$ was being retained in the micromodels.

Micromodel Visualization. All optical images of the micromodels were acquired with a Nikon Eclipse 2000TE epifluorescent microscope (Nikon, Melville, NY) using a $4 \times$ inverted objective at a spatial resolution of $1.6 \mu \mathrm{m}$, under both bright field mode and fluorescence mode using a GFP filter (excitation wavelength $=450-490 \mathrm{~nm}$, emission wavelength $=$ $500-550 \mathrm{~nm})$. The microscope was equipped with a motorized stage (Prior Scientific Instrument, Rockland, MA) and a digital monochrome charge-coupled device (CCD) camera (CoolSnap HQ2, Photometrics Inc., Tucson, AZ), both connected to a computer and controlled by NIS Elements imaging software
(Nikon, Melville, NY). A total of $70(10 \times 7)$ separate images were taken at selected time points for each experiment; an additional image from outside the pore network area was also acquired, and image correction was systematically applied to correct for nonuniform illumination prior to montaging the 70 separate images to form a single image which captured the entire $2 \mathrm{~cm} \times 1 \mathrm{~cm}$ pore network.

Synchrotron X-ray Microprobe (XMP) and X-ray Absorption Spectroscopy (XAS). X-ray microprobe fluorescence imaging was carried out at the synchrotron beamline 20-ID at the Advanced Photon Source, Argonne National Lab (beam size $3 \mu \mathrm{m} \times 7.5 \mu \mathrm{m}$, energy $12 \mathrm{KeV}$ for Fe and $17.9 \mathrm{KeV}$ for U). A Si (111) monochromator provided an energy resolution of $1 \mathrm{eV}$ at the $\mathrm{Fe} \mathrm{K}$ edge and $2.6 \mathrm{eV}$ at the $\mathrm{UL}_{3}$ edge. Micromodels were mounted in a secondary containment cell with a Kapton film window to facilitate X-ray measurements of U-containing samples. At the Fe K-edge, the energy of the Xrays was insufficient to penetrate the glass cover, so it was not possible to measure the Fe within the micromodel. Therefore, to map Fe distribution, the micromodels were sectioned under a $\mathrm{N}_{2}$ atmosphere in an anaerobic glovebox and the $\mathrm{Fe}$ in the pore network was mapped in cross section. X-ray fluorescence images of the micromodels and cross sections were recorded and used to choose points for subsequent measurement of Xray absorption near-edge spectroscopy (XANES) and extended X-ray absorption fine structure (EXAFS) at the Fe K-edge and the $\mathrm{U}$ L-edge. $\mathrm{Fe}$ and $\mathrm{U}$ data were taken in fluorescence mode with an Fe foil and a uranyl phosphate powder standard used respectively for online energy calibration. The EXAFS and XANES data were analyzed using the Athena interface to the IFEFFIT program package. ${ }^{34}$ For the near edge analysis, the valence was obtained using linear combination fits of normalized standard spectra to the normalized data.

\section{RESULTS AND DISCUSSION}

Microbial Colonization and Exposure to $U(V I)$ in Acetate/Fumarate Micromodel. Colonization of defined pore spaces within the micromodel by GFP-labeled $G$. sulfurreducens cells under flow conditions, with acetate and fumarate as the electron donor and acceptor, respectively, was monitored using bright field and fluorescence microscopy. By comparison between bright field and fluorescent images, it was apparent that sufficient $\mathrm{O}_{2}$ was present in the micromodel for maturation of all expressed GFP. In these pore networks, the majority of microbial growth occurred in the central mixing zone where conditions for biomass synthesis and respiration were most favorable with both electron donor and acceptor 

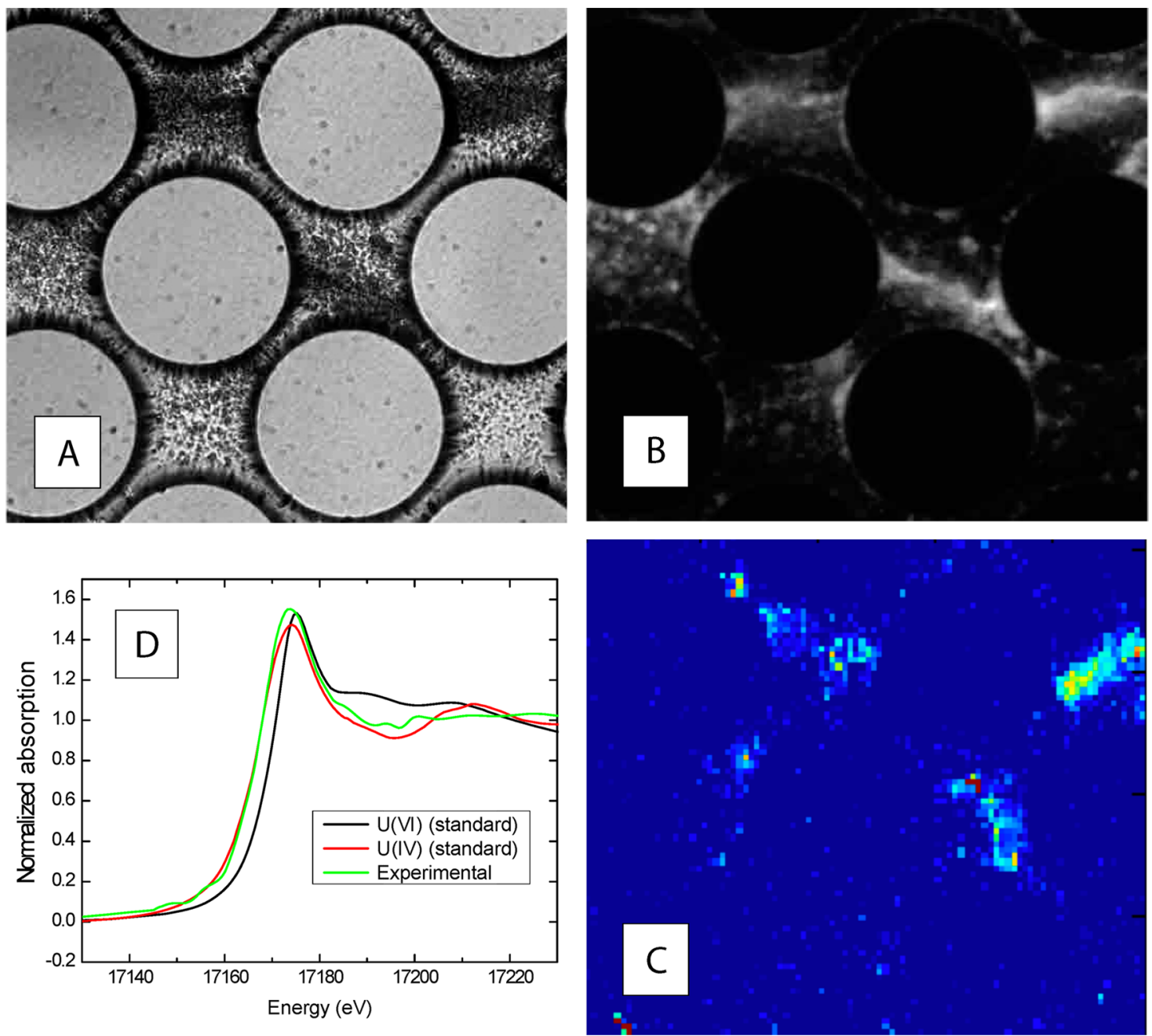

Figure 2. Micromodel containing biomass grown on acetate/fumarate. (A) Bright field image of biomass growing within the pore network, pillar diameter is $300 \mu \mathrm{m}$; (B) Identical area imaged using epifluorescence microscopy to reveal Geobacter biomass expressing GFP protein; (C) XMP uranium map; (D) XANES spectra of uranium hotspots identified in panel $\mathrm{C}$ with standards.
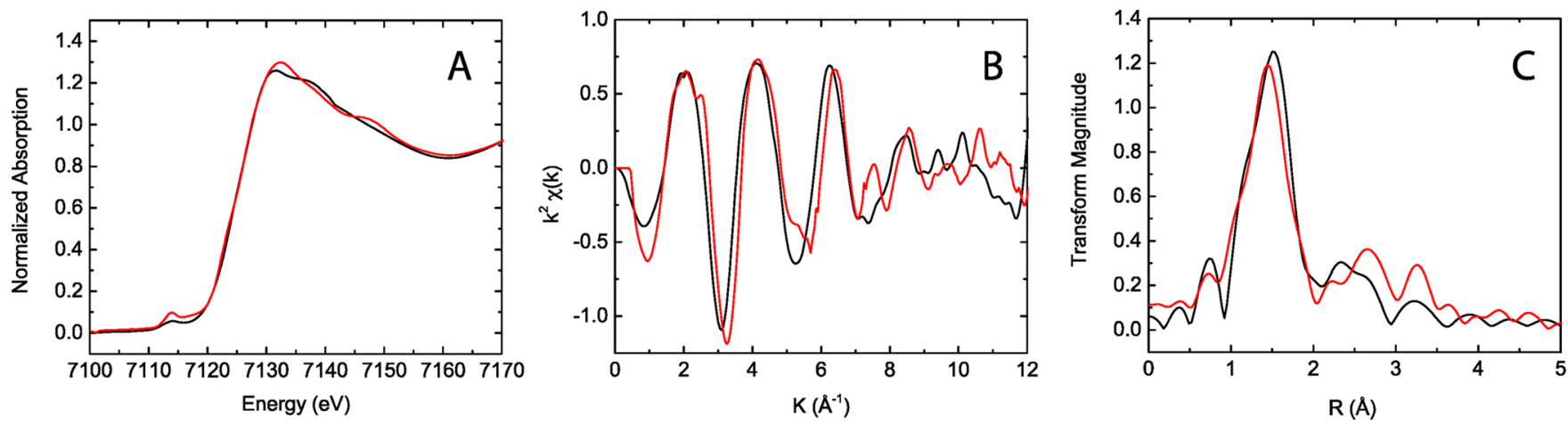

Figure 3. XANES spectra (A), EXAFS spectra (B), and the magnitude of the Fourier transform of the $k^{2}$ weighted EXAFS spectra over the $k$ range $2-11.5 \AA^{-1}$ (C) for a ferrihydrite standard (black) and the Fe(III) poorly crystalline phase that was precipitated within the pore network (red).

present (Figure 1). As growth continued over a period of 4 weeks, "fingers" of biomass extending from the downstream side of grains into pore spaces were observed, indicating the effects of flow-induced shear stress on microorganism spatial distributions. Similar biomass growth patterns in homogeneous micromodels have been observed using an anaerobic halorespiring microorganism ${ }^{20}$ and an aerobic bacterium. ${ }^{21}$
After the 4-week growth period, U(VI) was added to both influent media inlets as uranyl nitrate $(6 \mu \mathrm{mol} / \mathrm{L})$. The cells within the pore network were exposed to the modified media for a further 4 weeks, after which time flow was ceased, but the micromodels remained saturated. The average concentration of $\mathrm{U}$ retained in the micromodel was $1 \mu \mathrm{mol} / \mathrm{L}$ per day). Areas of the micromodel around the central mixing zone where most cell growth had occurred were identified based on optical 

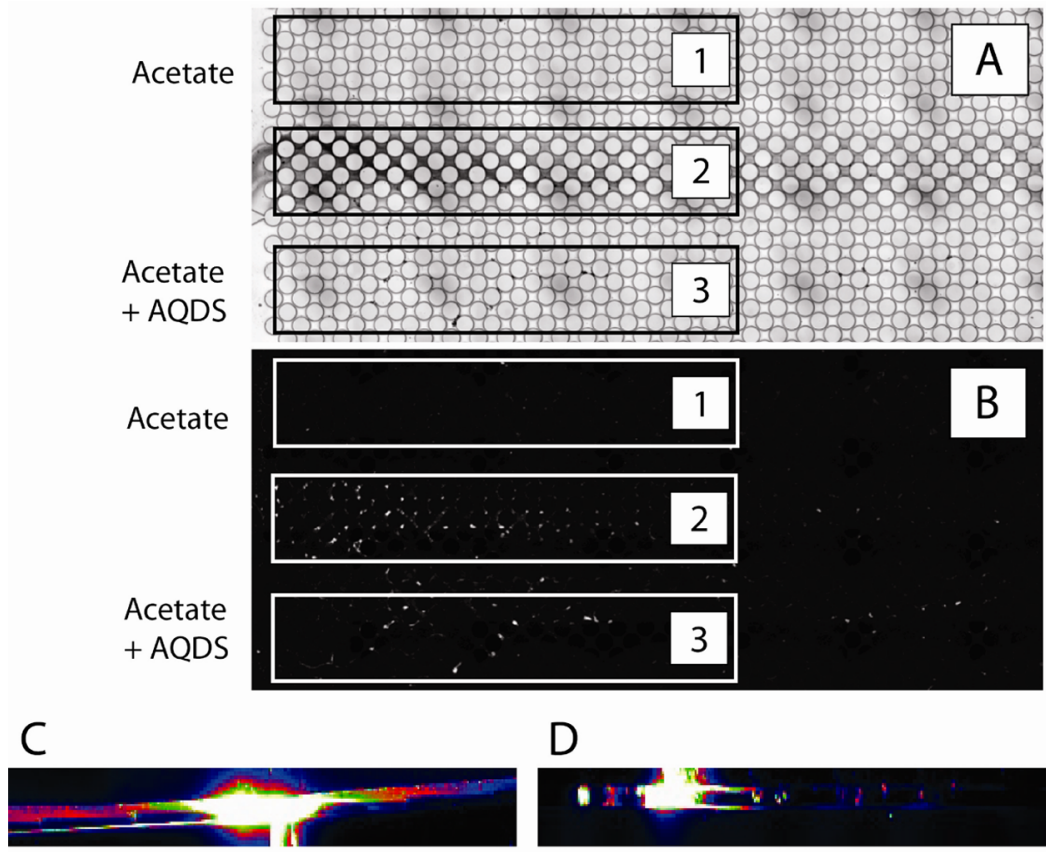

$\mathrm{D}$
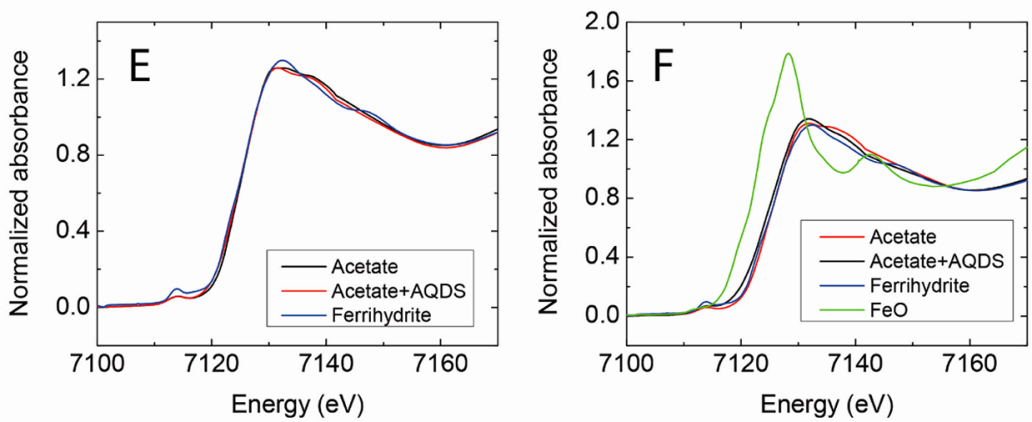

Figure 4. $\mathrm{Fe}(\mathrm{III})$ reduction within the pore network. (A) Bright field image of $\mathrm{Fe}(\mathrm{III})$ precipitate and biomass growing within the pore network, pillar diameter is $300 \mu \mathrm{m}$; (B) identical area imaged using epifluorescence microscopy to reveal Geobacter biomass expressing GFP protein. In (A) and (B), Box 1 corresponds to an area without biomass on the acetate side, Box 2 corresponds to the Fe precipitate with associated biomass, and Box 3 corresponds to an area with biomass away from the Fe precipitate on the acetate + AQDS side. (C) XMP iron map of etched micromodel channel (depth $=35 \mu \mathrm{m}$ ) in the absence of Geobacter biomass and (D) XMP iron map of etched micromodel channel (depth $=35 \mu \mathrm{m}$ ) in the presence of Geobacter biomass (in C and D, light colors indicate the highest concentrations of Fe and dark colors indicate the lowest). (E) XANES spectra of iron precipitate in absence of Geobacter biomass with standards. (F) XANES spectra of iron precipitate in presence of Geobacter biomass with standards.

images and the $\mathrm{U}$ distribution in these areas was mapped using $\mathrm{XMP}$ in fluorescence mode, above the U L-edge (Figure 2C). The distribution of $U$ in the pore network was closely but not uniformly correlated with areas of high biomass (Figure 2B and C). XANES spectra of the $U$ hot spots showed that the $U$ was present as a U(IV) species, indicating that bioreduction of the $\mathrm{U}(\mathrm{VI})$ by the G. sulfurreducens cells had occurred within the pore spaces (Figure 2D). Due to the low concentration of $U$ and the presence of water, it was not possible to obtain EXAFS spectra at the U L-edge to determine if the U(IV) was present as a uraninite or as mononuclear U(IV) "adsorbed" to the cells.

Microbial Colonization and U(VI) Exposure in Acetate/Fe-Oxide Micromodel. An Fe(II) rich anoxic solution was mixed with an $\mathrm{O}_{2}$-saturated solution to mimic the boundary between oxidized and reduced subsurface zones. Upon mixing, an Fe precipitate formed down the central mixing zone of the pore network. This precipitate effectively acted as an impermeable barrier down the center of the micromodel and prevented contact between the two solutions added through inlets on either side of the pore network. XANES/EXAFS spectroscopy of a cross section of the precipitate at the Fe Kedge revealed it to be a poorly crystalline $\mathrm{Fe}(\mathrm{III})$ oxide, with a structure very similar to that for ferrihydrite (Figure 3). G. sulfurreducens cells were subsequently introduced into the micromodel through both inlets and were able to colonize this mineral phase, using it as a terminal electron acceptor coupled to acetate oxidation. A second micromodel exposed to the same conditions in the absence of cells was maintained as a control. In addition to acetate, the electron shuttle AQDS was also provided via influent flow through one inlet, with the $\mathrm{Fe}$ precipitate restricting the AQDS to one side of the pore network. Cell clusters imaged using fluorescence microscopy (white areas indicated in Figure 4B, Box 2) were predominantly localized in the region of the $\mathrm{Fe}(\mathrm{III})$ precipitate (dark areas indicated in Figure 4A, Box 2) in the section of the pore network without AQDS, with no cell growth observed away from the $\mathrm{Fe}$ (III) oxide (Figure 4B, Box 1). In the pore network region with AQDS, some cell growth was observed spatially separated from the $\mathrm{Fe}(\mathrm{III})$ oxide, as indicated by Box 3 in Figure 4B, suggesting that the G. sulfurreducens cells were using 

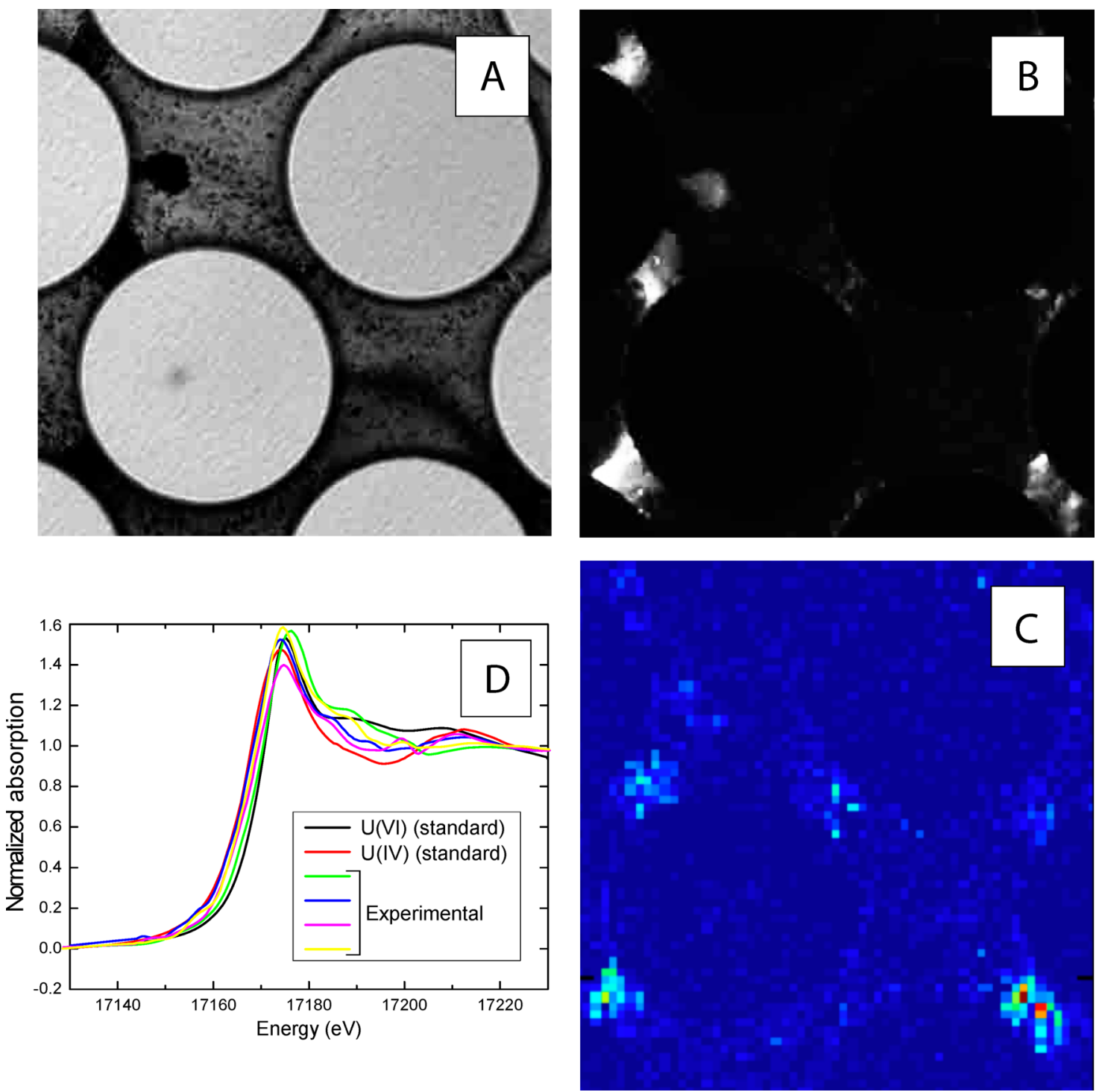

Figure 5. Micromodel containing biomass grown on precipitated Fe(III). (A) Bright field image of Fe(III) precipitate and biomass growing within the pore network, pillar diameter is $300 \mu \mathrm{m}$. (B) Identical area imaged using epifluorescence microscopy to reveal Geobacter biomass expressing GFP protein. (C) XMP uranium map. (D) XANES spectra of uranium hotspots identified in panel C with standards.

AQDS, instead of the $\mathrm{Fe}(\mathrm{III})$ oxide, as a terminal electron acceptor. $^{35}$

At this point, one micromodel was sacrificed and sectioned under anaerobic conditions to determine the distribution and oxidation state of the ferrihydrite-like precipitate in the pore network, after exposure to G. sulfurreducens cells, compared with the no-cell control (Figure $4 \mathrm{C}-\mathrm{F}$ ). The micromodel cross-section was mapped using XMP in fluorescence mode above the Fe K-edge (Figure 4C, control; and D, with cells).In the control micromodel without cells, significantly more of the precipitated $\mathrm{Fe}(\mathrm{III})$ phase remained than in the micromodel that had been exposed to G. sulfurreducens cells. However, the XMP map in Figure 4C shows that the Fe precipitate still completely blocked the pore network, even after exposure to the cells. A series of points spanning the Fe precipitate in both micromodels was selected for Fe K-edge XANES spectroscopy (Figure 4E and F). Figure 4E shows two example XANES spectra for the no-cell control micromodel from the section of the Fe precipitate that had been exposed to acetate only, and from the region of the Fe precipitate that had been exposed to both acetate and AQDS, with a ferrihydrite standard for comparison. The spectra from the control experiments were very similar to those of the standard, suggesting that the $\mathrm{Fe}$ precipitate remained as ferrihydrite. In the experiment with $G$. sulfurreducens cells present in both sides of the micromodel, the XANES edge position for the section of the Fe precipitate that had been exposed to AQDS was shifted to lower energy (Figure 4F). A linear combination fit of this XANES spectrum, using ferrihydrite and wustite as $\mathrm{Fe}$ (III) and $\mathrm{Fe}$ (II) standards, respectively, revealed that the Fe precipitate contained 10\% $\mathrm{Fe}(\mathrm{II})$. Therefore, enzymatic reduction and partial dissolution of $\mathrm{Fe}$ (III) had occurred in the section of the pore network that contained both G. sulfurreducens cells and AQDS, but some of the $\mathrm{Fe}(\mathrm{II})$ remained in association with the solid phase, possibly as sorbed $\mathrm{Fe}(\mathrm{II})$. However, the EXAFS spectrum remained ostensibly the same as that for ferrihydrite, suggesting that the presence of sorbed $\mathrm{Fe}$ (II) in these quantities did not result in a structural change in the $\mathrm{Fe}$ (III)-oxide mineral phase. Under no-flow (batch) conditions, G. sulfurreducens cells transform ferrihydrite to magnetite via goethite, in both the 
presence and absence of AQDS, with the rate and extent of the transformation dependent on the supply of $\mathrm{Fe}(\mathrm{II})$ to the system. ${ }^{36}$ Benner et al. also found that a different dissimilatory metal reducer, Shewanella putrefaciens $\mathrm{CN}-32$, transformed ferrihydrite into goethite and magnetite in a column system with advection (the flow rate was 2 orders of magnitude lower than in the present study), but the mineral transformation was inefficient with $80 \%$ of the residual Fe remaining in the ferric state at the end of the experiment. ${ }^{37}$ However, Hansel et al. ${ }^{38}$ found that, at low $\mathrm{Fe}(\mathrm{II})$ concentrations $(<0.3 \mathrm{mmol} / \mathrm{L})$ under advective flow, the loss of $\mathrm{Fe}$ (II) from solution was due to sorption onto ferrihydrite, not mineral transformation. ${ }^{38}$ Due to the relatively high flow rate and the low concentration of biomass used in this study, it is likely that the $\mathrm{Fe}$ (II) concentration produced by the G. sulfurreducens cells in the vicinity of the ferrihydrite was not high enough to induce secondary mineralization.

To assess the effect of spatially separated Fe-reducing microbes and reduced/oxidized Fe-bearing mineral phases on $\mathrm{U}$ redox cycling, a micromodel containing the $\mathrm{Fe}$ precipitate and G. sulfurreducens cells that had been growing with AQDS in one side of the pore network and without AQDS in the other side for 4 weeks, was exposed to FWM containing acetate (10 $\mathrm{mmol} / \mathrm{L})$ and uranyl nitrate $(6 \mu \mathrm{mol} / \mathrm{L})$ through both inlets. After exposure to the U(VI)-containing media for 4 weeks, flow was stopped and the saturated micromodels were imaged using $\mathrm{XMP}$ in fluorescence mode above the U L-edge (Figure 5). The darker regions in Figure $5 \mathrm{~A}$ that do not correspond to fluorescent clusters of biomass in Figure 5B represent the $\mathrm{Fe}$ (III) precipitate. The majority of the sorbed $\mathrm{U}$ (Figure $5 \mathrm{~B}$ and $\mathrm{C}$ ) is associated with the biomass and not the $\mathrm{Fe}$ precipitate. The XMP maps did not show any evidence for association of $\mathrm{U}$ with biogenic $\mathrm{Fe}$ (II) in the section of the micromodel that had been exposed to AQDS, suggesting that the concentration of adsorbed Fe(II) was not high enough to abiotically reduce $\mathrm{U}(\mathrm{VI})$. However, XMP mapping did show that there was a higher concentration of $U$ on the side of the micromodel that had previously been exposed to AQDS (data not shown). Localization of $U$ to this side of the micromodel is attributed to enhanced growth of G. sulfurreducens using both $\mathrm{Fe}(\mathrm{III})$ and AQDS as terminal electron acceptors. XANES analysis of $U$ hot spots in the pore network (Figure 5D) indicated the presence of both $\mathrm{U}(\mathrm{IV})$ and $\mathrm{U}(\mathrm{VI})$. Thus, unlike the acetate/fumarate micromodel that contained only $\mathrm{U}(\mathrm{IV})$ associated with the biomass (Figure 2D), a mixed valence state assemblage exists with $\mathrm{U}(\mathrm{IV})$ and $\mathrm{U}(\mathrm{VI})$ when biomass and $\mathrm{Fe}$ phases are colocalized in the acetate/Fe-oxide micromodel. This suggests the reaction and cycling of reduced U(IV) with $\mathrm{Fe}$ (III) phases.

The presence of $\mathrm{U}(\mathrm{VI})$ in the micromodel at a high enough concentration to detect using XANES indicates that some of it may have been associated with the $\mathrm{Fe}$ (III) phase. Previous batch studies have shown that $\mathrm{U}$ adsorbed to Fe(III) oxides, such as maghemite, remains as U(VI).$^{39}$ It is also possible that some of the microbially reduced U(IV) may have been oxidized by residual $\mathrm{Fe}(\mathrm{III}) .^{7-9}$ Ginder-Vogel et al. ${ }^{9}$ noted that the redox couples for $\mathrm{UO}_{2(\text { bio })} / \mathrm{U}(\mathrm{VI}$ ) and $\mathrm{Fe}(\mathrm{III})$ (hydr)oxide/Fe(II) occur at similar potentials under common groundwater conditions and confirmed the oxidation of $\mathrm{UO}_{2(\text { bio })}$ by ferrihydrite, according to eq $1 .{ }^{9}$

$$
\begin{gathered}
\mathrm{UO}_{2 \text { (biogenic) }}+2 \mathrm{Fe}(\mathrm{OH})_{3}+2 \mathrm{HCO}_{3}{ }^{-}+4 \mathrm{H}^{+} \\
\rightarrow \mathrm{UO}_{2}\left(\mathrm{CO}_{3}\right)_{2}{ }^{2-}(\mathrm{aq})+2 \mathrm{Fe}^{2+}(\mathrm{aq})+6 \mathrm{H}_{2} \mathrm{O}
\end{gathered}
$$

The rate-limiting steps in the oxidation reaction involved uraninite dissolution and reaction product transport. ${ }^{9}$ Thus, the reaction kinetics are likely to be enhanced under flow conditions as opposed to those observed in static systems. Given that ferrihydrite is the only $\mathrm{Fe}$ (III) phase present and the $\mathrm{pH}$ of the $\mathrm{HCO}_{3}{ }^{-}$-containing $\mathrm{FWM}$ is $\sim 7$, the mechanism of $\mathrm{U}(\mathrm{IV})$ oxidation may involve the formation of a U(VI) mineral phase in association with the U(IV), which would explain the mixed $U$ oxidation states observed in the XANES analysis of the U hot spots.

Implications. A range of pore-scale geochemical and physical parameters will determine the localization of microbial biomass in subsurface environments. These include (i) shear stresses within preferential flow paths; (ii) microenvironments where local biogeochemical "hotspots" arise resulting from localized mixing of nutrients and electron acceptors/donors required for growth; and (iii) the subsequent development of chemical gradients associated with microbial activity. Due to the highly localized nature of microbial growth and enzymatic processes in the subsurface porous media, biogeochemical reactions and products will be heterogeneously distributed. One implication of this is that measurements made at the bulk scale (such as using XAS to measure bulk sediments) will reflect an average over that particular spatial scale and the heterogeneity that exists within it. This may influence process interpretation as well as predictions of future biogeochemical behavior. This work suggests that predictive approaches must take into account the potential recalcitrance or inaccessibility of localized $\mathrm{Fe}$ (III) phases to enzymatic reduction within the subsurface and the subsequent impact on $U$ cycling, while the contribution of enzymatic $\mathrm{U}(\mathrm{VI})$ reduction performed by planktonic bacteria, away from Fe(III) phases, should also be considered.

\section{ASSOCIATED CONTENT}

\section{S Supporting Information}

Micromodel fabrication method, a schematic of the micromodel setup, and a schematic of $\mathrm{Fe}$ (III)-oxide precipitation at the boundary between oxidized and reduced subsurface zones. This information is available free of charge via the Internet at http://pubs.acs.org/.

\section{AUTHOR INFORMATION}

\section{Corresponding Author}

*Phone: (509)371-6380, e-mail: carolyn.pearce@pnnl.gov; mail: MS K8-96.

\section{Notes}

The authors declare no competing financial interest.

\section{ACKNOWLEDGMENTS}

This work was funded by PNNL Science Focus Area (SFA), Subsurface Biogeochemical Research (SBR) program, U.S. Department of Energy (DOE). Micromodel experiments were performed in Environmental Molecular Science Laboratory (EMSL), a national user facility supported by the DOE Office of Biological and Environmental Research (OBER) and located at PNNL. Use of the Advanced Photon Source, an Office of Science User Facility operated for the U.S. Department of Energy (DOE) Office of Science by Argonne National 
Laboratory, was supported by the U.S. DOE under Contract DE-AC02-06CH11357. We acknowledge Ken Kemner, ANL, for provision of the uranyl phosphate standard and Thomas Wietsma, PNNL, for his help with setting up the micromodels. We thank Charlie Werth, University of Illinois, for supporting the initial micromodel fabrication. We would also like to thank Kevin Rosso, PNNL, for his support and advice.

\section{REFERENCES}

(1) Borch, T.; Kretzschmar, R.; Kappler, A.; Cappellen, P. V.; GinderVogel, M.; Voegelin, A.; Campbell, K. Biogeochemical Redox Processes and their Impact on Contaminant Dynamics. Environ. Sci. Technol. 2009, 44 (1), 15-23.

(2) Suzuki, Y.; Kelly, S. D.; Kemner, K. M.; Banfield, J. F. Radionuclide contamination - Nanometre-size products of uranium bioreduction. Nature 2002, 419 (6903), 134.

(3) Burgos, W. D.; McDonough, J. T.; Senko, J. M.; Zhang, G. X.; Dohnalkova, A. C.; Kelly, S. D.; Gorby, Y.; Kemner, K. M. Characterization of uraninite nanoparticles produced by Shewanella oneidensis MR-1. Geochim. Cosmochim. Acta 2008, 72 (20), 49014915.

(4) Behrends, T.; Van Cappellen, P. Competition between enzymatic and abiotic reduction of uranium(VI) under iron reducing conditions. Chem. Geol. 2005, 220 (3-4), 315-327.

(5) Jang, J.-H.; Dempsey, B. A.; Burgos, W. D. Reduction of U(VI) by $\mathrm{Fe}(\mathrm{II})$ in the presence of hydrous ferric oxide and hematite: Effects of solid transformation, surface coverage, and humic acid. Water Res. 2008, 42 (8-9), 2269-2277.

(6) Jeon, B. H.; Dempsey, B. A.; Burgos, W. D.; Barnett, M. O.; Roden, E. E. Chemical reduction of U(VI) by $\mathrm{Fe}(\mathrm{II})$ at the solid-water interface using natural and synthetic Fe(III) oxides. Environ. Sci. Technol. 2005, 39 (15), 5642-5649.

(7) Wan, J.; Tokunaga, T. K.; Brodie, E.; Wang, Z.; Zheng, Z.; Herman, D.; Hazen, T.; Firestone, M. K.; Sutton, S. R. Reoxidation of bioreduced uranium under reducing conditions. Environ. Sci. Technol. 2005, 39 (16), 6162-6169.

(8) Ginder-Vogel, M.; Criddle, C.; Fendorf, S. Thermodynamic constraints on the oxidation of biogenic $\mathrm{UO}_{2}$ by $\mathrm{Fe}$ (III) (hydr)oxides. Environ. Sci. Technol. 2006, 40, 3544-3550.

(9) Ginder-Vogel, M.; Stewart, B.; Fendorf, S. Kinetic and Mechanistic Constraints on the Oxidaiton of Biogenic Uraninite by Ferrihydrite. Environ. Sci. Technol. 2010, 44 (1), 163-169.

(10) O’Loughlin, E. J.; Kelly, S. D.; Cook, R. E.; Csencsits, R.; Kemner, K. M. Reduction of uranium(VI) by mixed iron(II)/iron(III) hydroxide (green rust): Formation of $\mathrm{UO}_{2}$ nanoparticles. Environ. Sci. Technol. 2003, 37, 721-727.

(11) Missana, T.; Maffiotte, C.; Garcia-Gutierrez, M. Surface reaction kinetics between nanocrystalline magnetite and uranyl. J. Colloid Interface Sci. 2003, 261, 154-160.

(12) Sani, R. K.; Peyton, B. M.; Dohnalkova, A. C.; Amonette, J. E. Reoxidation of Reduced Uranium with Iron(III) (Hydr)Oxides under Sulfate-Reducing Conditions. Environ. Sci. Technol. 2005, 39, 20592066.

(13) Li, L.; Gawande, N.; Kowalsky, M. B.; Steefel, C. I.; Hubbard, S. S. Physicochemical Heterogeneity Controls on Uranium Bioreduction Rates at the Field Scale. Environ. Sci. Technol. 2011, 45 (23), 99599966.

(14) McKinley, J. P.; Zachara, J. M.; Wan, J.; McCready, D. E.; Heald, S. M. Geochemical Controls on Contaminant Uranium in Vadose Hanford Formation Sediments at the 200 Area and 300 Area, Hanford Site, Washington. Vadose Zone J. 2007, 6 (4), 1004-1017.

(15) Liu, C.; Zachara, J. M.; Zhong, L.; Heald, S. M.; Wang, Z.; Jeon, B. H.; Fredrickson, J. K. Microbial Reduction of Intragrain U(VI) in Contaminated Sediment. Environ. Sci. Technol. 2009, 43, 4928-4933.

(16) Scheibe, T. D.; Fang, Y.; Murray, C. J.; Roden, E. E.; Chen, J.; Chien, Y.-J.; Brooks, S. C.; Hubbard, S. S. Transport and biogeochemical reaction of metals in a physically and chemically heterogeneous aquifer. Geosphere 2006, 2 (4).
(17) Li, L.; Steefel, C. I.; Kowalsky, M. B.; Englert, A.; Hubbard, S. S. Effects of physical and geochemical heterogeneities on mineral transformation and biomass accumulation during a biostimulation experiment at Rifle, Colorado. J. Contam. Hydrol. 2010, 112 (1-4), $45-63$.

(18) Li, L.; Steefel, C. I.; Yang, L. Scale dependence of mineral dissolution rates within single pores and fractures. Geochim. Cosmochim. Acta 2008, 72 (2), 360-377.

(19) Werth, C. J.; Zhang, C. Y.; Brusseau, M. L.; Oostrom, M.; Baumann, T. A review of non-invasive imaging methods and applications in contaminant hydrogeology research. J. Contam. Hydrol. 2010, 113 (1-4), 1-24.

(20) Nambi, I. M.; Werth, C. J.; Sanford, R. A.; Valocchi, A. J. Porescale analysis of anaerobic halorespiring bacterial growth along the transverse mixing zone of an etched silicon pore network. Environ. Sci. Technol. 2003, 37 (24), 5617-5624.

(21) Zhang, C.; Kang, Q.; Wang, X.; Zilles, J. L.; Müller, R. H.; Werth, C. J. Effects of Pore-Scale Heterogeneity and Transverse Mixing on Bacterial Growth in Porous Media. Environ. Sci. Technol. 2010, 44 (8), 3085-3092.

(22) Willingham, T. W.; Werth, C. J.; Valocchi, A. J. Evaluation of the Effects of Porous Media Structure on Mixing-Controlled Reactions Using Pore-Scale Modeling and Micromodel Experiments. Environ. Sci. Technol. 2008, 42 (9), 3185-3193.

(23) Singh, R.; Olson, M. S. Transverse Mixing Enhancement due to Bacterial Random Motility in Porous Microfluidic Devices. Environ. Sci. Technol. 2011, 45 (20), 8780-8787.

(24) Zhang, C.; Dehoff, K.; Hess, N.; Oostrom, M.; Wietsma, T. W.; Valocchi, A. J.; Fouke, B. W.; Werth, C. J. Pore-Scale Study of Transverse Mixing Induced $\mathrm{CaCO}_{3}$ Precipitation and Permeability Reduction in a Model Subsurface Sedimentary System. Environ. Sci. Technol. 2010, 44 (20), 7833-7838.

(25) Mayhew, L. E.; Webb, S. M.; Templeton, A. S. Microscale Imaging and Identification of $\mathrm{Fe}$ Speciation and Distribution during Fluid-Mineral Reactions under Highly Reducing Conditions. Environ. Microbiol. 2011, 45 (10), 4468-4474.

(26) Yang, L.; Steefel, C. I.; Marcus, M. A.; Bargar, J. R. Kinetics of $\mathrm{Fe}(\mathrm{II})$-Catalyzed Transformation of 6-line Ferrihydrite under Anaerobic Flow Conditions. Environ. Sci. Technol. 2010, 44 (14), 5469-5475.

(27) Gu, B.; Wu, W.-M.; Ginder-Vogel, M. A.; Yan, H.; Fields, M. W.; Zhou, J.; Fendorf, S.; Criddle, C. S.; Jardine, P. M. Bioreduction of Uranium in a Contaminated Soil Column. Environ. Sci. Technol. 2005, 39 (13), 4841-4847.

(28) Sharp, J. O.; Lezama-Pacheco, J. S.; Schofield, E. J.; Junier, P.; Ulrich, K. U.; Chinni, S.; Veeramani, H.; Margot-Roquier, C.; Webb, S. M.; Tebo, B. M.; Giammar, D. E.; Bargar, J. R.; Bernier-Latmani, R. Uranium speciation and stability after reductive immobilization in aquifer sediments. Geochim. Cosmochim. Acta 2011, 75 (21), 64976510.

(29) Boyanov, M. I.; Fletcher, K. E.; Kwon, M. J.; Rui, X.; O'Loughlin, E. J.; Löffler, F. E.; Kemner, K. M. Solution and Microbial Controls on the Formation of Reduced U(IV) Species. Environ. Sci. Technol. 2011, 45 (19), 8336-8344.

(30) Chomsurin, C.; Werth, C. J. Analysis of pore-scale nonaqueous phase liquid dissolution in etched silicon pore networks. Water Resour. Res. 2003, 39 (9), 1265.

(31) Lovley, D. R.; Phillips, E. R. Novel mode of microbial energy metabolism: organic carbon oxidation coupled to dissimilatory reduction of iron or manganese. Environ. Microbiol. 1988, 54, 14721480.

(32) Fredrickson, J. K.; Zachara, J. M.; Kennedy, D. W.; Dong, H.; Onstott, T. C.; Hinman, N. W.; Li, S.-M. Biogenic iron mineralization accompanying the dissimilatory reduction of hydrous ferric oxide by a groundwater bacterium. Geochim. Cosmochim. Acta 1998, 62 (19/20), $3239-3257$

(33) Hernandeza, M. E.; Newman, D. K. Extracellular electron transfer. Cell. Mol. Life Sci. 2001, 58, 1562-1571. 
(34) Ravel, B.; Newville, M. ATHENA, ARTEMIS, HEPHAESTUS; data analysis for X-ray absorption spectroscopy using IFEFFIT. $J$. Synchrotron Radiat. 2005, 12 (4), 537-541.

(35) Cervantes, F. J.; Duong-Dac, T.; Ivanova, A. E.; Roest, K.; Akkermans, A. D. L.; Lettinga, G.; Field, J. A. Selective enrichment of Geobacter sulfurreducens from anaerobic granular sludge with quinones as terminal electron acceptors. Biotechnol. Lett. 2003, 25 (1), 39-45.

(36) Coker, V. S.; Bell, A. M. T.; Pearce, C. I.; Pattrick, R. A. D.; van der Laan, G.; Lloyd, J. R. Time-resolved synchrotron powder X-ray diffraction study of magnetite formation by the $\mathrm{Fe}(\mathrm{III})$-reducing bacterium Geobacter sulfurreducens. Am. Mineral. 2008, 93 (4), 540547.

(37) Benner, S. G.; Hansel, C. M.; Wielinga, B. W.; Barber, T. M.; Fendorf, S. Reductive Dissolution and Biomineralization of Iron Hydroxide under Dynamic Flow Conditions. Environ. Sci. Technol. 2002, 36, 1705-1711.

(38) Hansel, C. M.; Benner, S. G.; Neiss, J.; Dohnalkova, A. C.; Kukkadapu, R. K.; Fendorf, S. Secondary mineralization pathways induced by dissimilary iron reduction of ferrihydrite under advective flow. Geochim. Cosmochim. Acta 2003, 67 (16), 2977-2992.

(39) Latta, D. E.; Gorski, C. A.; Boyanov, M. I.; O’Loughlin, E. J.; Kemner, K. M.; Scherer, M. M. Influence of Magnetite Stoichiometry on $\mathrm{U}^{\mathrm{VI}}$ Reduction. Environ. Sci. Technol. 2012, 46, 778-786. 